\title{
High efficiency solid-state sensitized heterojunction photovoltaic device
}

\author{
Mingkui Wang ${ }^{a, 1}$, Jingyuan Liu ${ }^{b, 2}$, Ngoc-Le Cevey-Ha ${ }^{a, 1}$, Soo-Jin Moon ${ }^{a, 1}$, \\ Paul Liska ${ }^{a, 1}$, Robin Humphry-Baker ${ }^{\mathrm{a}, 1}$, Jacques-E. Moser ${ }^{\mathrm{a}, 1}$, \\ Carole Grätzel $^{\mathrm{a}, 1}$, Peng Wang ${ }^{\mathrm{b}, *}$, Shaik M. Zakeeruddin ${ }^{\mathrm{a}, * *, 1}$, \\ Michael Grätzel ${ }^{\mathrm{a}, * *, 1}$
}
a LPI, Institute of Chemical Sciences and Engineering, École Polytechnique Fédérale de Lausanne, 1015 Lausanne, Switzerland
b State Key Laboratory of Polymer Physics and Chemistry, Changchun Institute of Applied Chemistry, Chinese Academy of Sciences, Changchun 130022, China

Received 11 December 2009; received in revised form 3 February 2010; accepted 1 April 2010 Available online 11 May 2010

\section{KEYWORDS \\ Solar cell; \\ Sensitizer; \\ Photoinduced \\ absorption \\ spectroscopy; \\ Photovoltage \\ transient \\ spectroscopy; \\ Charge \\ recombination}

\begin{abstract}
Summary The high molar extinction coefficient heteroleptic ruthenium dye, $\mathrm{NaRu}\left(4,4^{\prime}\right.$-bis(5(hexylthio)thiophen-2-yl)-2,2'-bipyridine) (4-carboxylic acid-4'-carboxylate-2,2'-bipyridine) $(\mathrm{NCS})_{2}$, exhibits certified $5 \%$ electric power conversion efficiency at AM 1.5 solar irradiation $\left(100 \mathrm{~mW} \mathrm{~cm}^{-2}\right)$ in a solid-state dye-sensitized solar cell using 2,2',7,7'-tetrakis-(N,N-dipmethoxyphenylamine)-9,9'-spirobifluorene (spiro-MeOTAD) as the organic hole-transporting material. This demonstration elucidates a class of photovoltaic devices with potential for low-cost power generation.

(c) 2010 Elsevier Ltd. All rights reserved.
\end{abstract}

The dye-sensitized nanocrystalline solar cell (DSC) offers special opportunities in the realm of renewable energy sources primarily stemming from its use of low-cost mate-

\footnotetext{
* Corresponding author. Fax: +86 43185262953.

** Corresponding authors. Fax: +41216936100. E-mail addresses: peng.wang@ciac.jl.cn (P. Wang), shaik.zakeer@epfl.ch (S.M. Zakeeruddin), michael.graetzel@epfl.ch (M. Grätzel).

1 Fax: +41216936100.

2 Fax: +8643185262953 .
}

rials and its lack of stringent conditions required for device manufacturing [1]. In the quest for new sensitizers leading to an enhancement of the photon-to-electron conversion efficiency, the creation of new ruthenium dyes still remains a promising option. Indeed, recent improvements in the design and synthesis of new dyes have made it possible to obtain greater than $11 \%$ light-to-energy conversion efficiencies. The majority of these newly developed sensitizers involve polypyridyl-type complexes of ruthenium [2-4]. Advantages in terms of improved sealing properties and long-term cell stability can be realized by replacing the liquid electrolytes utilized in DSC by a solid-state 


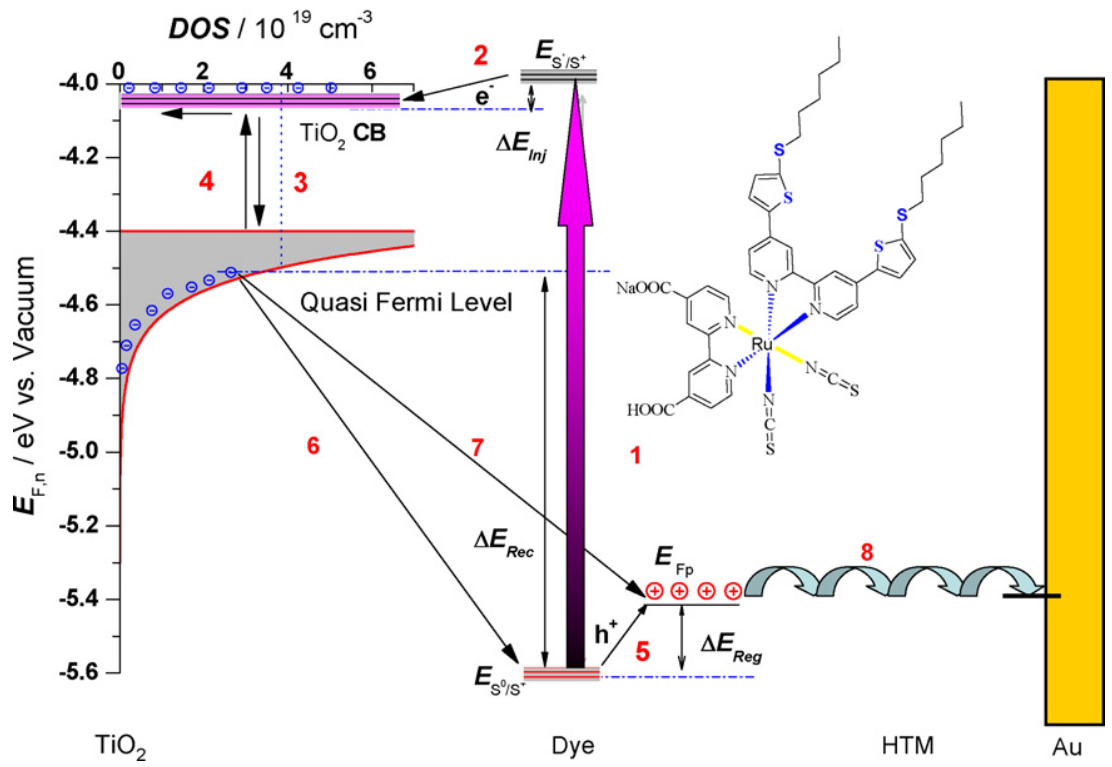

Figure 1 Schematic illustration of the electron-transfer processes occurring in the solid-state dye-sensitized heterojunction: process 1, light-induced excitation of the chromophore; process 2, electron injection into the conduction band of the $\mathrm{TiO}_{2}$ semiconductor; processes 3 and 4, trapping and detrapping of electrons in the $\mathrm{TiO}_{2}$; process 5 , dye regeneration via hole transfer to spiro-MeOTAD; processes 6 and 7, the direct recombination of primarily separated charges and the secondary recombination process between the injected electron and the oxidized spiro-MeOTAD; process 8 , holes hopping in the HTM. Also shown are band energies of different components. The inset shows the molecular structure of C106 dye.

hole-transporting material (HTM) to fabricate solid-state dye-sensitized solar cells (SSDSC). The initial successful demonstration of the feasibility of making SSDSC devices reported in 1998 announced a $0.74 \%$ power conversion efficiency [5]. Recent advances in the photovoltaic performance of SSDSC have augmented the power conversion efficiencies obtained to the range of $4-4.8 \%$ [6-11]. There are two key issues to address in order to increase the relatively low efficiencies found in SSDSC. One basic problem is the poorer light harvesting found in solid-state devices compared to that found in liquid-based devices, resulting from the use of a thinner nanocrystalline film (i.e., $\cong 2-3 \mu \mathrm{m}$ ) in the fabrication of the former devices. The other impediment to producing more efficient SSDSC devices is the rapid recombination dynamics found at the dye-sensitized heterojunction (see Fig. 1) [12,13]. Some approaches have been proposed to improve light harvesting and to reduce interfacial recombination, including the development of new sensitizers and coadsorbents [12-18]. It is well documented that sensitizers containing hydrophobic spacers work efficiently in DSC devices [14-18]. Tuning the length of the hydrophobic spacers is an important aspect in the design of new sensitizers. This optimization has been previously realized by incorporating a $\pi$-conjugation linker molecule such as a thiophene or a thienothiophene derivative into the chromophoric framework [14-18].

A promising molecular engineering approach to overcome the dilemma of low light harvesting due to the thinner titania films used in SSDSC (utilized to ensure adequate pore filling) is to increase the molar extinction coefficient of the sensitizer employed. Herein, we report on high efficiency SSDSC devices based on a ruthenium complex sensitizer, $\mathrm{NaRu}\left(4,4^{\prime}\right.$-bis(5-(hexylthio)thiophen-2- yl)-2,2'-bipyridine) (4-carboxylic acid-4'-carboxylate-2,2' bipyridine) $(\mathrm{NCS})_{2}$, coded as C106 [16] (see Fig. 1). Photovoltaic parameters were measured for C106 derivatized SSDSC and compared to devices fabricated using the analogous Z907Na dye. Laser transient and photoinduced absorption (PIA) techniques have also been used to analyze the kinetics of SSDSC devices employing C106 sensitizer. The insertion of thiophene units in-between the alkyl chain and the pyridine units augments the molar extinction coefficient of the sensitizer by increasing the $\pi$ conjugation. The dye's hydrophobicity likewise augments due to its alkyl chains, rendering better pore filling by the HTM, resulting in more efficient dye regeneration and a lower recombination rate. The molar extinction coefficient $(\varepsilon)$ of $\mathrm{C} 106$ at $550 \mathrm{~nm}$ is $18,700 \mathrm{M}^{-1} \mathrm{~cm}^{-1}$. Under identical conditions, the widely used analogous Z907Na dye exhibits an absorption band at $521 \mathrm{~nm}$ with an extinction coefficient of $\varepsilon=12,200 \mathrm{M}^{-1} \mathrm{~cm}^{-1}$. Sensitization of the thin nanocrystalline titania film by $\mathrm{C} 106$ dye leads to the expected enhancement of the device's performance in comparison to cells sensitized by Z907Na. This enhanced performance is attributed in part to the improvement of C106's light harvesting properties relative to Z907Na. In Fig. 2 the $J-V$ characteristics of a SSDSC device fabricated using the $\mathrm{C} 106$ dye and a $1.9 \mu \mathrm{m}$ thick transparent titania film (consisting of $\cong 20 \mathrm{~nm}$ sized $\mathrm{TiO}_{2}$ particles) and spiro-MeOTAD as HTM exhibits a $J_{\mathrm{sc}}$ of $8.27 \mathrm{~mA} \mathrm{~cm}^{-2}$, a $V_{\text {oc }}$ of $848 \mathrm{mV}$ and a FF of 0.71 , yielding an impressive $5 \%$ efficient SSDSC. This is the first time that a certified efficiency of $5 \%$ (measured at the National Renewable Energy Laboratory (USA)) under standard global AM1.5 solar conditions $\left(100 \mathrm{~mW} \mathrm{~cm}^{-2}\right)$ is being reported for a solid-state DSC device. The increase in open circuit voltage of the C106 SSDSC device compared to that of the analogous Z907Na device $(749 \mathrm{mV})$ 


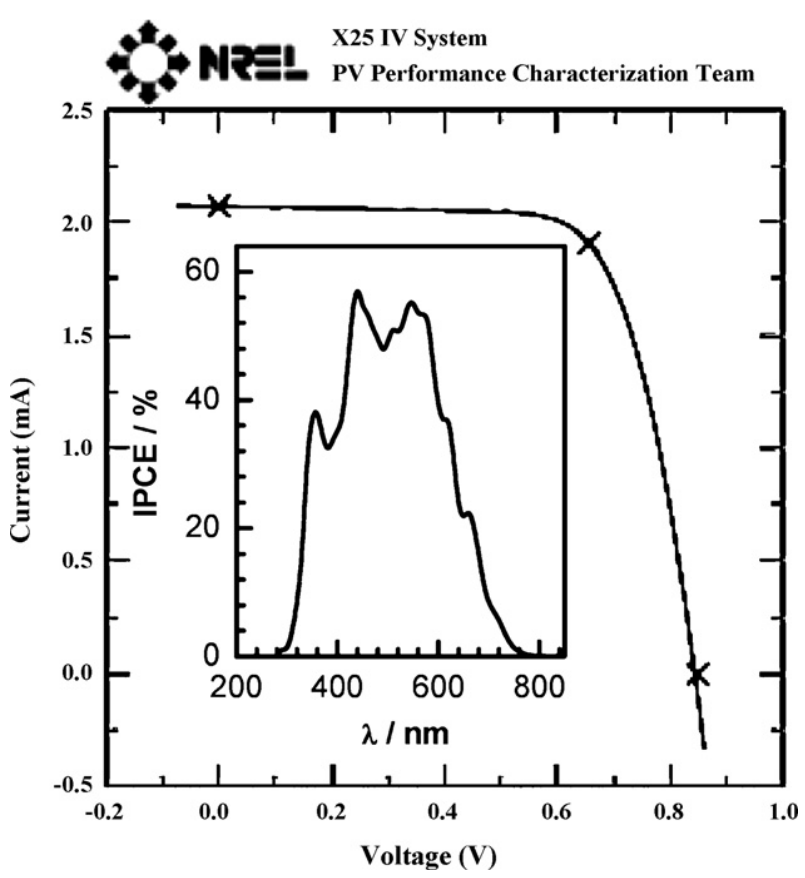

Figure $2 J-V$ characteristics of a SSDSC sensitized by C106 dye measure by the NREL photovoltaic calibration laboratory under standard reporting conditions, i.e. illumination with $A M$ $1.5 \mathrm{G}$ sunlight (intensity $100 \mathrm{~mW} \mathrm{~cm}^{-2}$ ) and $298 \mathrm{~K}$ temperature. The inset exhibits its photocurrent action spectrum. Cell active area tested (with a mask): $0.2505 \mathrm{~cm}^{2}$.

can be attributed to a longer comparative recombination lifetime (see supporting information, Fig. S1), contributing to the overall enhanced efficiency of C106 devices $[9,10]$. The incident photon-to-current conversion efficiency (IPCE) spectrum exceeds $40 \%$ over the spectral range from 420 to $580 \mathrm{~nm}$ reaching a maximum of approximately $60 \%$ at $500 \mathrm{~nm}$ (see the inset in Fig. 2).

Laser transient absorbance measurements were performed to monitor the dynamics of the recombination of electrons injected in the conduction band of $\mathrm{TiO}_{2}\left(e_{\mathrm{cb}}{ }^{-}\right)$ with the oxidized dye $\left(\mathrm{S}^{+}\right)$, of hole injection from $\mathrm{S}^{+}$into the HTM, and of the indirect recombination process taking place between the oxidized HTM and $e_{\mathrm{cb}}{ }^{-}$. Fig. 3A displays the temporal evolution of the absorbance measured at $\lambda=570 \mathrm{~nm}$ of a transparent $\mathrm{C} 106$ dye-sensitized $\mathrm{TiO}_{2}$ film upon pulsed laser excitation at $510 \mathrm{~nm}$. In the absence of HTM, photo-excitation and ultrafast electron injection leads to the bleaching of the dye's ground state (negative transient signal, Fig. 3A, red curve). From the magnitude of the bleaching signal and the absorbed number of laser photons it can be inferred that charge injection occurs with a quantum yield close to 1 . When dye stained titania film pores were filled with the HTM the dye is regenerated by hole injection in the organic solid resulting in the appearance of the typical absorption of spiro-MeOTAD cation radicals (Fig. 3A, blue trace). This hole transfer is completed within a few nanosceconds and hence occurs within the laser excitation pulse $[19,20]$. In this case the laser excitation energy fluence was quite high $\left(200 \mu \mathrm{J} \mathrm{cm}^{-2}\right.$ per pulse) and resulted on average in the injection of much more than one electron per $\mathrm{TiO}_{2}$ particle and in the fast decay of the observed
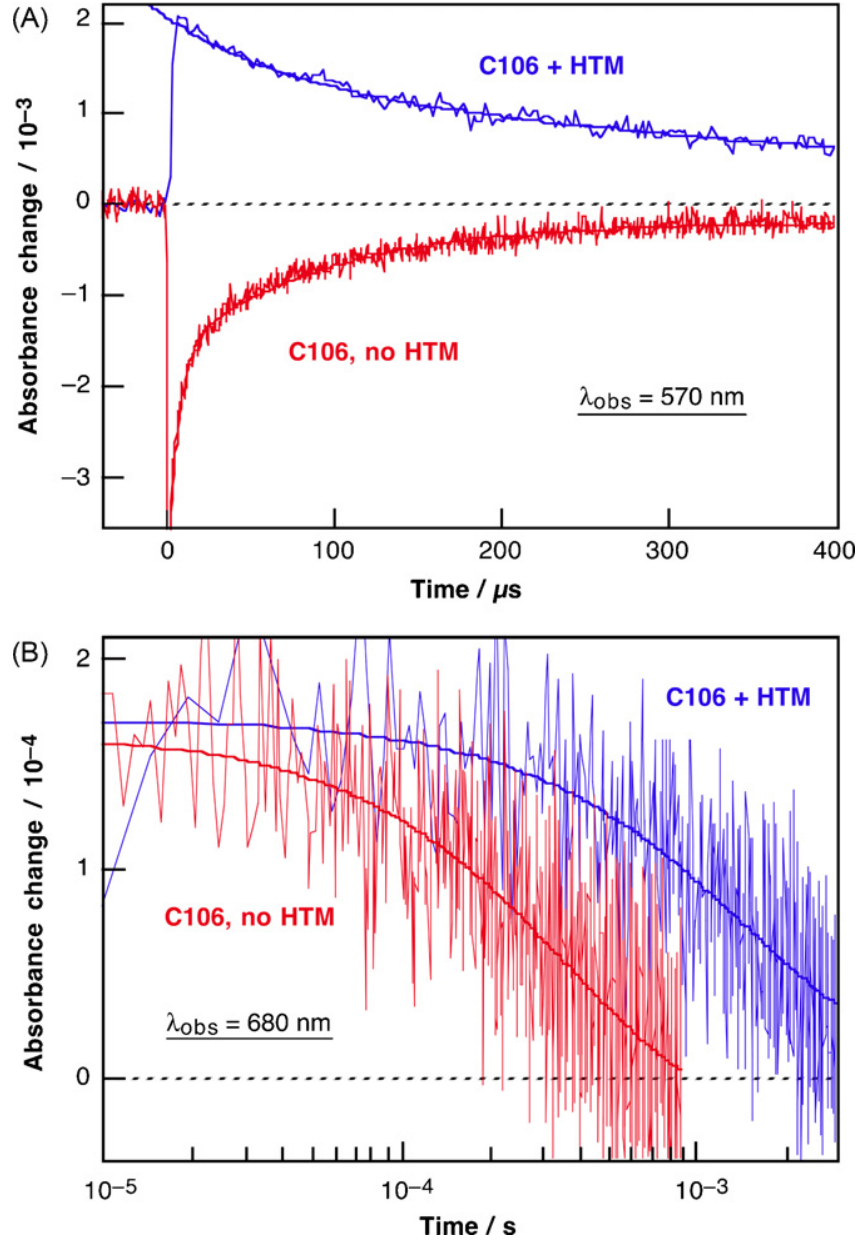

Figure 3 Temporal profiles of the transient absorbance measured at $\lambda=570 \mathrm{~nm}(\mathrm{~A})$ and at $\lambda=680 \mathrm{~nm}(\mathrm{~B})$ upon pulsed laser excitation ( $\lambda=510 \mathrm{~nm}$ wavelength, $5 \mathrm{~ns}$ full width half-maximum pulse duration, $30 \mathrm{~Hz}$ repetition rate) on samples comprised of C106 dye adsorbed on nanocrystalline $\mathrm{TiO}_{2}$ films in the presence (blue traces) and in the absence (red traces) of spiro-MeOTAD hole transport material. Excitation pulse energy fluence was $200 \mu \mathrm{J} \mathrm{cm}^{-2}$ (A) and $20 \mu \mathrm{J} \mathrm{cm}^{-2}$ (B). Smooth solid lines are double exponential fits of experimental data.

signals. Fig. 3B shows transient absorbance traces recorded at $\lambda_{a b s}=680 \mathrm{~nm}$. This time, energy fluence was attenuated down to $20 \mu \mathrm{J} \mathrm{cm}^{-2}$ per pulse, so as to ensure that at most one electron was injected per $\mathrm{TiO}_{2}$ particle during each excitation pulse. In such conditions, recombination kinetics is expected to be identical to those characterizing functional systems under solar irradiation. In the absence of HTM (Fig. 3B, red trace), absorbance at $680 \mathrm{~nm}$ was attributed mainly to the dye oxidized state species $S^{+}$, a small contribution to the signal being due to conduction band electrons. Decay of the absorbance resulted from the direct recombination process $\left(S^{+}-e_{\mathrm{cb}}{ }^{-}\right)$, with a halfreaction time of $t_{1 / 2}=200 \mu \mathrm{s}$, significantly larger than what was observed upon excitation by higher fluence laser pulses (Fig. 3A). In the presence of spiro-MeOTAD (Fig. 3B, blue trace), the signal is dominated by the absorbance of oxidized spiro-MeOTAD. The decay time constant $t_{1 / 2}=1 \mathrm{~ms}$ measured in this case thus reflects the kinetics of the recom- 

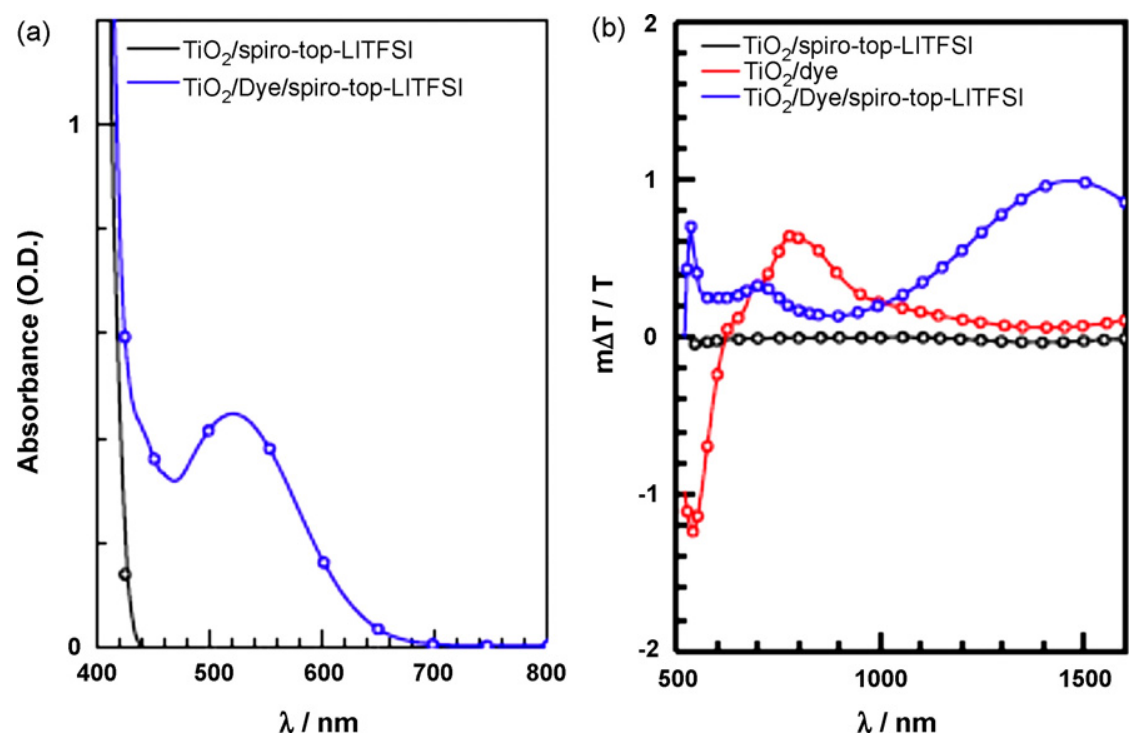

Figure 4 (a) The visible absorption spectra of the thin $\mathrm{TiO}_{2}$ film filled with spiro-MeOTAD (black line) and in presence of C106 dye (blue line). (b) The photo-induced absorption (PIA) spectra of nano-structured $\mathrm{TiO}_{2}$ films $(1.9 \mu \mathrm{m}$ thick): red line, spectra for a C106 dye-sensitized $\mathrm{TiO}_{2}$ film in air; blue line, for a dye-sensitized $\mathrm{TiO}_{2}$ film in the presence of spiro-MeOTAD, and black line, for a bare $\mathrm{TiO}_{2}$ (no dye) infiltrated with solid hole conductor.

bination between holes in the HTM and conduction band electrons. The indirect recombination observed here with the spiro-MeOTAD solid-state hole conductor suggests this process is responsible for the performance loss compared to electrolyte-based DSC where electron lifetime is on the order of three to hundreds of ms range [17]. Since the electron injection in the SSDSC device with C106 dye is fast, the IPCE value is limited by the light harvesting efficiency $\eta \mathrm{LH}$ (process 1) which inferred from Fig. 4a $\left(\eta_{\mathrm{LH}}=1-10^{A}, A\right.$ being the absorbance) to be $65 \%$ for a single passage of light through the film.

Unraveling of the details of spectral and kinetic information of the devices was likewise undertaken by employing PIA techniques. Fig. 4b shows the PIA spectra using the dye adsorbed titania film, deposited on FTO glass covered with a compact $\mathrm{TiO}_{2}$ layer, in the presence or absence of the HTM. In the absence of the HTM, the PIA spectrum (red line) shows clearly the differential spectrum of C106 upon formation of the dye oxidized state, with a bleaching of the main absorption band at $538 \mathrm{~nm}$ (the ground state MLCT absorption) and an absorption peak at $807 \mathrm{~nm}$ (the oxidized state dye, $\mathrm{C106}^{+}$) [21-23]. Upon addition of the solid-state hole conductor, the PIA spectrum changes significantly. The absorption peak at $712 \mathrm{~nm}$ arises from the formation of the oxidized spiroMeOTAD (spiro-MeOTAD ${ }^{+}$, Fig. S2) in addition to a small contribution from $\mathrm{C} 106^{+}$. From the known extinction coefficients of the three species (spiro-MeOTAD ${ }^{+}, \mathrm{C} 106$ and C106 ${ }^{+}$), which are responsible for the optical changes [24-26], one derives the spiro-MeOTAD $/ \mathrm{C106}^{+}$ratio, from the two curves, to be close to $0.85 \pm 0.05$ indicating a very efficient hole-transfer process. The dye-sensitized nanocrystalline film without spiro-MeOTAD exhibits a shorter estimated PIA signal lifetime than that found in presence of HTM over the spectra range from 500 to $1500 \mathrm{~nm}$ (Fig. S3), due to a fast dye regeneration.
In conclusion, we have presented a highly efficient solidstate DSC sensitized by a heteroleptic polypyridyl ruthenium complex coded as C106 in which (hexylthio)-thiophene units have been inserted between the pyridine moieties and the alkyl chains leading to higher molar extinction coefficient and an increase in the charge recombination lifetime relative to SSDSC devices employing the analogous Z907Na dye. Through judicious molecular design in the development of the C106 dye, an encouraging certified 5\% power conversion efficiency was achieved. It has been demonstrated that increasing the molar extinction coefficient of sensitizers and reducing the indirect recombination of the oxidized spiro-MeOTAD species with the photo-injected electron is an elegant strategy to improve the photovoltaic performance of solid-state dye-sensitized solar cells.

\section{Experimental}

In the present work, C106 was used as an efficient sensitizer for solid-state DSCs, following synthetic procedures reported earlier [16]. Solar cell fabrication and characterizations were performed according to prior literature [10]. The PIA spectra of the various cells were recorded over a wavelength range of approximately $500-1500 \mathrm{~nm}$ following a (on/off) photo-modulation using a $9 \mathrm{~Hz}$ square wave emanating from a blue LED. White probe light from a halogen lamp was used as an illumination source. The recombination rate constants were determined by employing transient photovoltage decay measurement techniques $[10,12]$. $\mathrm{TiO}_{2}|\mathrm{C} 106| \mathrm{HTM}$ samples used in the laser transient absorbance measurements were obtained by peeling off the gold cathode layer of solar cells identical to those used in photo-electrochemical measurements. Samples were excited by nanosecond laser pulses produced by a 
broad-band optical parametric oscillator (OPO GWU-355), pumped by a frequency-tripled Q-switched Nd:YAG laser (Continuum Powerlite 7030). Excitation pulses $(\lambda=510 \mathrm{~nm}$ wavelength, $30 \mathrm{~Hz}$ repetition rate, pulse width at half-height of $5 \mathrm{~ns}$ ) were attenuated by neutral density filters to reduce pulse fluence on the sample. The probe light from a Xe arc lamp was passed through an interference filter, various optical elements, the sample, and a grating monochromator before being detected by a fast photomultiplier tube, only 3 dynodes of which were used.

\section{Acknowledgements}

This publication is based on work supported by the Center for Advanced Molecular Photovoltaics (Award No KUS-C1015-21), made by King Abdullah University of Science and Technology (KAUST). Financial support from the Swiss National Science Foundation is also gratefully acknowledged. PW and JL thank the National Key Scientific Program (No. 2007CB936700) for the financial support. We are grateful to Mr. P. Comte for $\mathrm{TiO}_{2}$ nanoparticles preparations and Mr. Jean-David Decoppet for helping in performing the NREL measurements.

\section{Appendix A. Supplementary data}

Supplementary data associated with this article can be found, in the online version, at doi:10.1016/j.nantod.2010.04.001.

\section{References}

[1] O’Regan, M. Grätzel, Nature 353 (1991) 737.

[2] M. Nazeeruddin, F. De Angelis, S. Fantacci, A. Selloni, G. Viscardi, P. Liska, S. Ito, B. Takeru, M. Grätzel, J. Am. Chem. Soc. 127 (2005) 16837.

[3] Y. Chiba, A. Islam, Y. Watanabe, R. Komiya, N. Koide, L. Han, Jpn. J. Appl. Phys. 45 (Part 2) (2006) L638.

[4] F. Gao, Y. Wang, D. Shi, J. Zhang, M. Wang, X. Jing, R. HumphryBaker, P. Wang, S.M. Zakeeruddin, M. Grätzel, J. Am. Chem. Soc. 130 (2008) 10720.

[5] U. Bach, D. Lupo, P. Comte, J. Moser, F. Weissortel, J. Salbeck, H. Spreitzer, M. Grätzel, Nature 395 (1998) 583.

[6] J. Krüger, R. Plass, L. Cevey, M. Piccirelli, M. Grätzel, U. Bach, Appl. Phys. Lett. (2001) 2085.

[7] L. Schmidt-Mende, U. Bach, R. Humphry-Baker, T. Horiuchi, H. Miura, S. Ito, S. Uchida, M. Grätzel, Adv. Mater. 17 (2005) 813.

[8] H. Snaith, A. Moule, C. Klein, K. Meerholz, R.H. Friend, M. Grartzel, Nano Lett. 7 (2007) 3372.

[9] M. Wang, M. Xu, D. Shi, R. Li, F. Gao, G. Zhang, Z. Yi, R. Humphry-Baker, P. Wang, S.M. Zakeeruddin, M. Grätzel, Adv. Mater. 20 (2008) 4460.

[10] M. Wang, C. Grätzel, S. Moon, R. Humphry-Baker, N. RossierIten, S.M. Zakeeruddin, M. Grätzel, Adv. Funct. Mater. 19 (2009) 2163.

[11] M. Wang, S. Moon, M. Xu, K. Chittibabu, P. Wang, N. CeveyHa, R. Humphry-Baker, S.M. Zakeeruddin, M. Grätzel, Small 6 (2009) 319.

[12] M. Wang, P. Chen, R. Humphry-Baker, S.M. Zakeeruddin, M. Grätzel, ChemPhysChem 10 (2009) 290.

[13] F. Fabregat-Santiago, J. Bisquert, L. Cevey, P. Chen, M. Wang, S.M. Zakeeruddin, M. Grätzel, J. Am. Soc. Chem. 131 (2009) 558.
[14] F. Gao, Y. Wang, J. Zhang, D. Shi, M. Wang, R. Humphry-Baker, P. Wang, S.M. Zakeeruddin, M. Grätzel, Chem. Commun. (2008) 2635.

[15] C. Chen, J. Chen, S. Wu, J. Li, C. Wu, K. Ho, Angew. Chem. 120 (2008) 7452;

C. Chen, J. Chen, S. Wu, J. Li, C. Wu, K. Ho, Angew. Chem. Int. Ed. 47 (2008) 7342.

[16] Y. Cao, Y. Bai, Q. Yu, Y. Cheng, S. Liu, D. Shi, F. Gao, P. Wang, J. Phys. Chem. C 113 (2009) 6290.

[17] B. O’Regan, K. Bakker, J. Kroeze, H. Smit, P. Sommeling, J. Durrant, J. Phys. Chem. B 110 (2006) 17155.

[18] N. Koumura, Z. Wang, S. Mori, M. Miyashita, E. Suzuki, K. Hara, J. Am. Chem. Soc. 128 (2006) 14256.

[19] U. Bach, Y. Tachibana, J.E. Moser, S.A. Haque, J.R. Durrant, M. Grätzel, D.R. Klug, J. Am. Chem. Soc. 121 (1999) 7445.

[20] J.E. Moser, M. Grätzel, in: V. Balzani, I.R. Gould (Eds.), Electron Transfer in Chemistry, vol. 5, Wiley-VCH, New York, 2001, pp. 589-644.

[21] G. Boschloo, A. Hagfeldt, Inorg. Chim. Acta 361 (2008) 729.

[22] S. Pelet, J.-E. Moser, M. Grätzel, J. Phys. Chem. B 104 (2000) 1791.

[23] T. Heimer, E. Heilweil, C. Bignozzi, G. Meyer, J. Phys. Chem. A 104 (2000) 4256.

[24] H. Snaith, R. Humphry-Baker, P. Chen, I. Cesar, S.M. Zakeeruddin, M. Grätzel, Nanotechnology 19 (2008) 424003.

[25] U. Cappe, E. Gibson, A. Hagfeldt, G. Boschloo, J. Phys. Chem. C 113 (2009) 6275.

[26] I. Ding, N. Tétreault, J. Brillet, B. Hardin, E. Smith, S. Rosenthal, F. Sauvage, M. Grätzel, M. McGehee, Adv. Funct. Mater. 19 (2009) 2431.

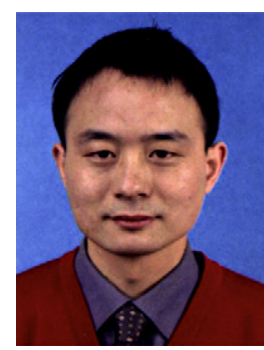

Dr. Mingkui Wang studied physical chemistry at the Harbin Institute of Technology, P.R. China, and obtained his PhD (with Prof. Shaojun Dong) in physical chemistry from the Chinese Academy of Science in 2004. He joined the group of Prof. Ulrich Stimming, Technischen Universität München in 2005 as an Alexander von Humboldt Fellow. Then he joined the group of Prof. Michael Gätzel at the Swiss Federal Institute of Technology Lausanne (EPFL) as a postdoctoral fellow. His research interests include solar cells, renewable power sources, and nanomaterials.

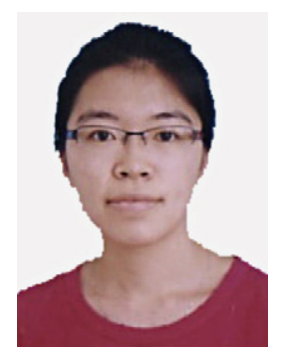

Jingyuan Liu received her BS in applied chemistry from Heilongjiang University in 2005 and is now pursing her PhD on applied chemistry in Harbin Engineering University. Since 2008, she joined the group led by Prof. Peng Wang at Changchun Institute of Applied Chemistry, Chinese Academy of Sciences as a joint PhD student. Her current research interest is synthesis and characterization of organic optoelectronic materials.

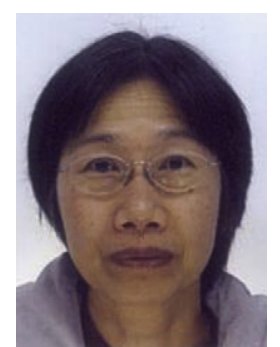

Dr. CEVEY-HA Ngoc-Le studied chemical engineering at the Swiss Federal Institute of Technology Lausanne (EPFL) and obtained her PhD degree (with Prof. Er. Sz Kovats) in analytical chemistry in 1982. She did a post-doctoral work in UC Berkeley (material department) with Prof. Fuerstenau from 1982 to 1983. After a break for the children, she joined the group of Prof. Michael Gräetzel since 1996. Her research focused on high performance and stability of liquid and solid solar cells. 


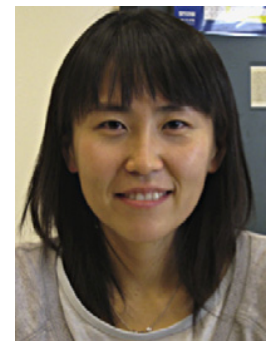

Soo-Jin Moon received her BS degree in chemical engineering from Inha University in 2001 and her MS degree in material science and engineering from Gwangju Institute of Science and Technology in 2003. Currently she is a PhD student in chemistry at the Swiss Federal institute of Technology under Prof. M. Gratzel. Her research interests include characterization of the sensitizers in dyesensitized solar cell and cell fabrication.

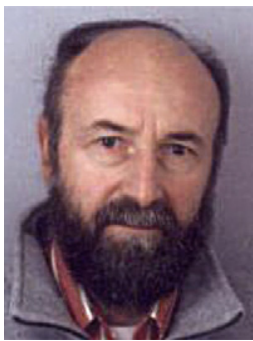

Dr.-Ing. Paul Liska studied mechanical engineering at Institute of Technology in Zurich. He worked from 1976 to 1986 in Research of Climatology, Fluid Mechanics and new physical simulation methods of regional atmospheric flows at EPFL-Civil Engineering. He joined Prof. M. Grätzel group in 1986 as a research assistant and $\mathrm{PhD}$ student for development of a new $\mathrm{TiO}_{2}$ sensitized solar cells. He obtained his PhD degree in 1994 and thereafter continuing as a research scientist in the same group. He is interested in solar and renewable energy research field and he is active in the development of DSC large-scale fabrication/processing method in close connection with industrial partners.

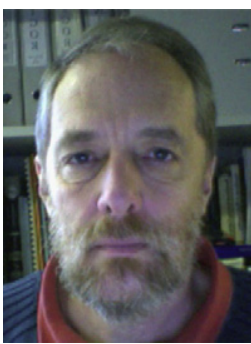

Dr. Robin Humphry-Baker undertook his undergraduate studies in chemistry at the University of Southampton. He extended his interest in photochemistry by exploring the subject of the photodegradation of keratin fibers, leading to a $\mathrm{PhD}$ degree in 1977. In the same year he was invited to join the laboratory of Prof. M. Grätzel at the EPFL in Switzerland. His research interests cover all topics of photophysics and spectroscopy.

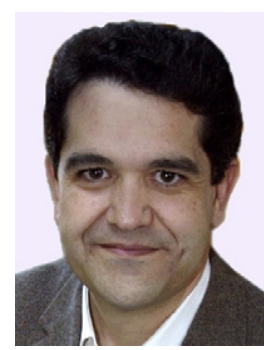

Prof. Jacques-E. Moser received in 1982 an MSc degree in chemical engineering from the Ecole Polytechnique Fédérale de Lausanne (EPFL, Switzerland), and in 1986 a PhD from the same university. After two stays at Concordia University and at the Canadian Centre for Picosecond Laser Spectroscopy in Montreal (Canada), he joined the Eastman Kodak Corporate Research Laboratories in Rochester (NY, USA) and later collaborated towards the foundation of the NSF Center for Photoinduced Charge Transfer at the University of Rochester. He has been leading since 1991 at EPFL a research team working in the fields of redox photochemistry and time-resolved interfacial laser spectroscopy. He was appointed lecturer of physical chemistry at EPFL in 1992 and was awarded the habilitation in 1998. He is a titular professor since 2005 and is currently heading the School of Chemistry and Chemical Engineering of EPFL.

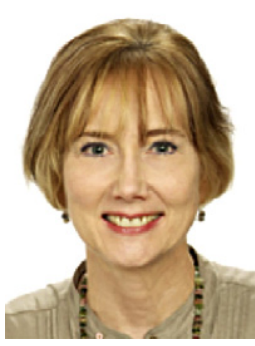

Dr. Carole Grätzel obtained her PhD in physical chemistry in 1978 from Rice University in Houston, Texas. She is employed as a research assistant at the Swiss Federal Institute of Technology in Lausanne, Switzerland. Her research domains include photocatalysis and dye-sensitized solar cell technology.

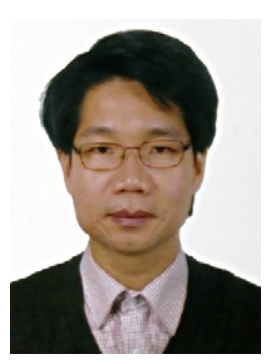

Prof. Peng Wang is a professor at Changchun Institute of Applied Chemistry, Chinese Academy of Sciences. He obtained his PhD in Chinese Academy of Sciences in 2001 and spent the subsequent four and half years as a postdoctoral fellow at Swiss Federal Institute of Technology and University of Cambridge. After that he worked as a visiting scientist for 5 months at the Institute of Polymer and Organic Solids at University of California at Santa Barbara. His present research focuses on design and synthesis of exotic organic materials in bionic nanoarchitechures for light energy conversion and closely related charge and energy transfer processes.

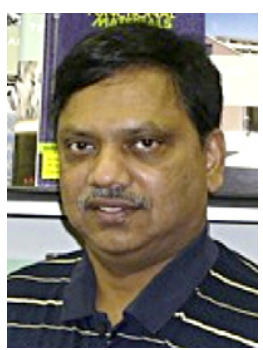

Dr. Shaik M. Zakeeruddin received his PhD from Osmania University, India in 1989. After that he joined Prof. Graetzel's group at - Swiss Federal Institute of Technology Lausanne (EPFL) as a postdoc and continuing as a senior scientist. The main area of his research is related to nanomaterials, solar energy conversion, electrochromic displays, ionic liquids, lithium ion batteries, lightemitting diodes and biosensors. Expert in designing and development of dyes, ionic liquids and interfacial engineering of metal oxide surfaces to enhance the photovoltaic performance and stability. He has published more than 150 peer-reviewed scientific papers and is the inventor of 20 patents.

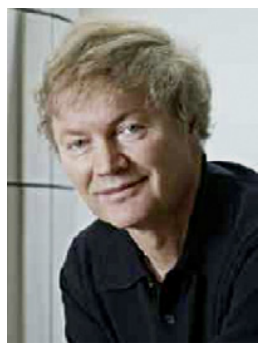

Prof. Michael Grätzel is a professor at the Ecole Polytechnique de Lausanne where he directs the laboratory of photonics and interfaces, pioneered studies of electron and energy transfer reactions in mesoscopic systems, a field where he has an outstanding track record and has maintained leadership on the global scale through several decades. Grätzel's infatuation with the mesoscopic dimension started early on in his carrier. Investigating photo-induced energy and electron transfer reactions in micellar systems, he discovered the unique quenching kinetics of solubilized fluorophores and used the local electrostatic field present at the micellar surface to control the dynamics of photo-induced electron transfer reactions. His publications include over 800 research papers in peer-reviewed scientific journals and 60 reviews or invited book chapters. He is the inventor or co-inventor of over 50 patents and editor, author or co-author of three books. His publications have received close to 60,000 citations ( $h$-index 116 ) ranking him amongst the most highly cited scientists in the world. He has received numerous prestigious awards, including the Balzan prize, the Harbey Prize, the Faraday Medal of the British Royal Society of Chemistry, the Dutch Havinga award, the ENI-Italgas prize and the Gerischer award. He received a doctor's degree in natural science from the Technical University Berlin and honorary doctors degrees from the Universities of Delft, Uppsala and Turin. 